\title{
HARNESSING DIGITAL WORKFLOWS FOR CONSERVING HISTORIC PLACES
}

\author{
M. Santana Quintero \\ Carleton Immersive Media Studio (CIMS), 1125 Colonel by drive, Ottawa, On, K1S 5B6 Canada, Mario.santana@ carleton.ca
}

\author{
Commission VI, WG VI/4
}

\begin{abstract}
KEY WORDS: Digital Workflows for heritage conservation, IT documentation, risk preparedness, Bagan, Egypt, Bahrain, Nepal, built heritage, natural hazards, 3D imaging, Recording, Photogrammetry, EDM, Computer-Aided Drawing, Conservation.
\end{abstract}

\begin{abstract}
:
Recording the physical characteristics of historic structures and landscapes is a cornerstone of preventive maintenance, monitoring and conservation. The information produced by such work assists the decision-making process for property owners, site managers, public officials, and conservators. Rigorous documentation may also serve a broader purpose: over time, it becomes the primary mean s by which scholars and the public apprehend a site that has since changed radically or disappeared. These records also serve as posterity and monitoring records in the event of catastrophic or gradual loss of the heritage resource.
\end{abstract}

\section{INTRODUCTION}

Good practices in heritage conservation are based on timely, relevant and accurate information about the conditions, materials and transformation of built heritage. Therefore, documentation, recording and analysis of heritage sites is an essential part for their management and conservation.

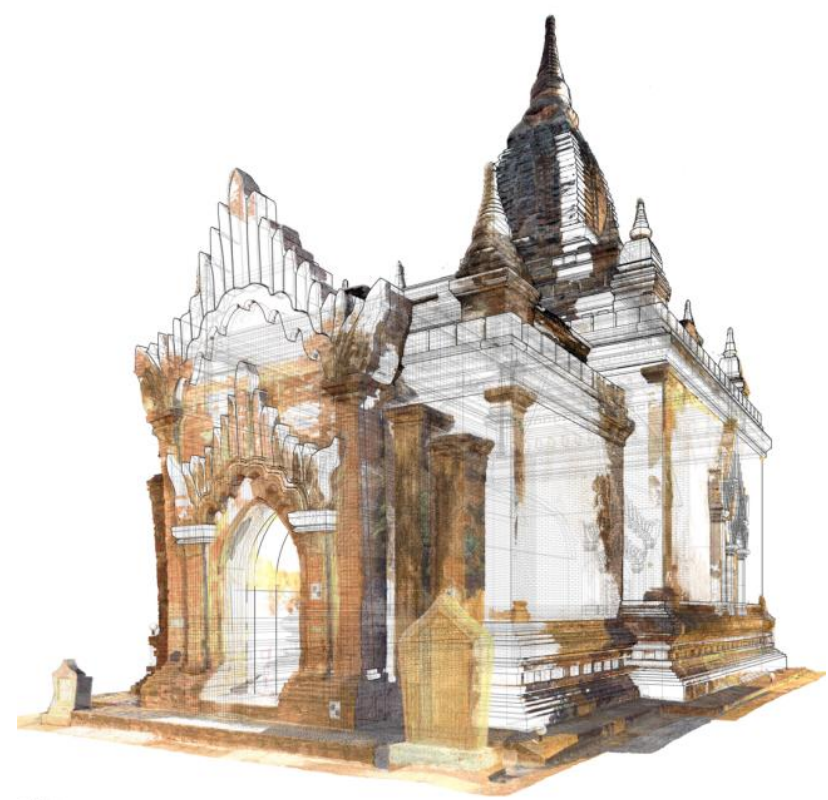

Figure 1: Building information model of Loka Hteik Pan temple, Bagan, Myanmar [1].

Furthermore, recording and Documentation of cultural heritage is experiencing a growing innovation, which is equally matched by the alarming rate of destruction by natural events, conflicts and negligence.

This paper underlays several multidisciplinary transcontinental collaborations for the comprehensive documentation of heritage places.
New tools have appeared in the last decades including: 3D scanning, rapid prototyping, high dynamic range spherical and infra-red imagery, affordable drone photography, augmented and virtual reality, and computer rendering in multiple dimensions.

These tools are giving visions and data that are all at once enticing and even sometimes, deceptive. Their applications are used in conservation education, research, risk assessment, and planning and design. The past generation had only basic tools like the film camera, paper, pencil, tape measures and slide rules. However, today we can carry computers with cameras in our pockets.

- Understand the role of visual information gathering in conservation of built heritage, with an eye to national and international standards for such work.

- Understand the challenges in conserving built heritage for World Heritage

- Review the strengths and limitations of recording techniques.

- Analyze the character defining elements attributing value to built heritage using these techniques.

- Analyze the condition (state of conservation) of built heritage using these techniques.

- Understand the relationship between recording and good conservation decision-making.

- Learn how to integrate information gathered through these techniques into coherent presentations.

- Effectively work in teams throughout the workshop, ultimately completing a graphic record of the sites.

In contemporary built heritage conservation, digital workflows are increasingly being used as tools to capture, generate, visualize and manage built heritage. These tangible resources are at imminent risk from inherent and external causes, which can drastically and/or slowly damage tangible heritage features. This paper provides design methodology priorities for implementing effective acquisition of posterity records, in order to ensure the appropriate collection, processing and sharing of heritage information. The design method is aimed at safeguarding the 
values of these places for future generations and eventual repair, maintenance and physical conservation.

Exposure to first-hand heritage recording projects, in collaboration with intergovernmental organizations, private foundations, governments, and consulting companies, has provided the adequate knowledge and experience for the following contribution. The employment of IT supported techniques and capacity building strategies for a holistic documentation are presented using four cases studies in Myanmar, Egypt and Morocco.

These digital workflows were employed in the described on-field recording activities in the case studies are freely available and are off-the-shelf (COTS) made applications.

\subsection{Opportunities and challenges}

Three main factors can summarize the challenges and opportunities for the implementation of digital workflows in the conservation of historic places.

The increasing "physical Integrity threated\}, dealing with potential identified and unknown (unidentified) built heritage resources that can disappear. As well as, the number of significantly sites affected disasters at an alarming rate by conflicts and natural.

Also, the effect of organizational Impact when adopting new technologies. Organizations dealing with the protection and management of historic places are not capable to meet the need of documenting these sites with existing mechanism (eg. Technical, institutional capacity, financial, social, security, etc.).

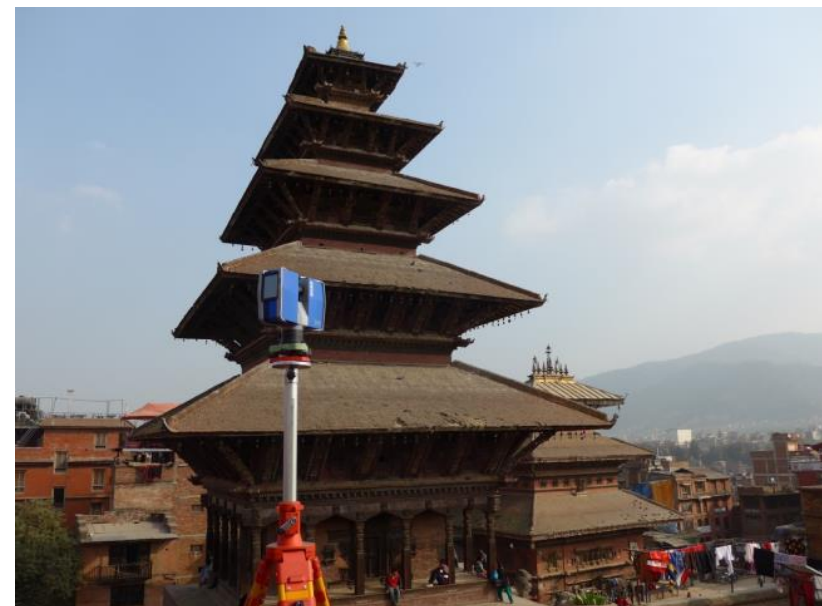

Figure 2: using a 3D scanner to record Nyatapola temple, Bhaktapur, Nepal.

In terms of the integrity of information, many major organizations with the capacity to use advanced digital workflows, limit their work to record the outer appearance. Numerous projects only focus on collecting only information about the outer appearance (surface). The knowledge of the assembly construction is equally important, as to understand how the detail (e.g.. the masonry wall, a vault, etc) are constructed. This accumulate knowledge is essential to ensure that the message in appropriately transmitted.

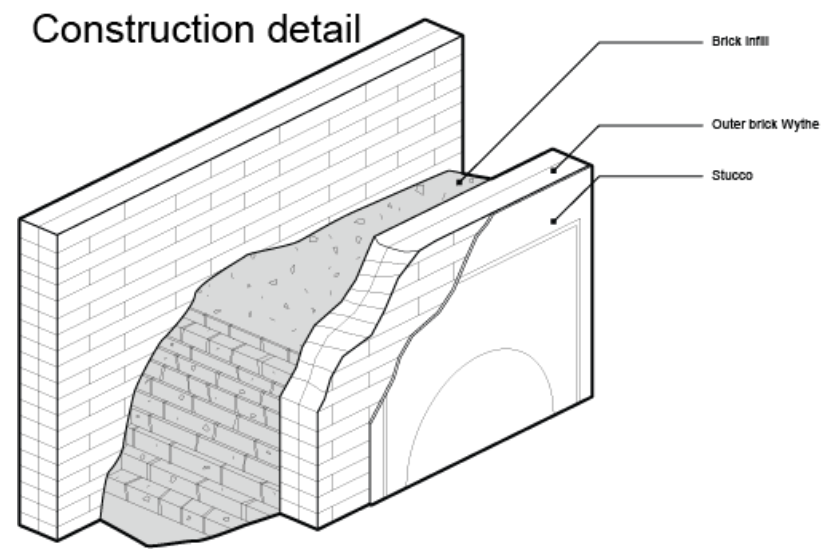

Figure 3: construction detail of historic masonry in Bagan, Myanmar [1]

Finally, limits (increasing threats and fragmentation of data), challenges (scale enlargement and development of new themes in cultural heritage), and perspectives (increasing pace of innovation, in cultural heritage conservation) are discussed in detail considering the international framework and current debate.

\section{DIGITAL WORKFLOWS FOR CONSERVATION}

According to the Standards and Guidelines for the Conservation of Historic Places in Canada, Conservation is defined as "all actions or processes that are aimed at safeguarding the characterdefining elements of an historic place so as to retain its heritage value and extend its physical life. This may involve Preservation, Rehabilitation, Restoration, or a combination of these actions or processes"[2].

Therefore, a digital workflow should insure relevant and sufficient information relevant to understand the historic places values and be able to extend their physical life by identifying character defining elements.

Further on the international scale and according to the UN website: "On September 25th 2015, countries adopted a set of goals to end poverty, protect the planet, and ensure prosperity for all as part of a new sustainable development agenda. Each goal has specific targets to be achieved over the next 15 years. "[3].

The Goal target 11.4 emphasises the global commitment for "Strengthen efforts to protect and safeguard the world's cultural and natural heritage"[3].

Further, the draft ICOMOS Action Plan 'Cultural Heritage and Localizing the SDGs' [4] explains that this goal target will be achieved in the overall conservation of the historic city by identifying indicators that could be monitor over time to either appreciate an improvement or deterioration of the heritage value.

The concept and role of digital workflows for recording, processing and disseminating information for the conservation of heritage places have evolved substantially in the years 
Specifically, the Venice Charter (1964)[5], requires that the documentation of monuments requires a high level of quality, ensuring a precise reproduction of the subject and its context. These statements have been already ascertained from the very essence of heritage conservation charters, as for Article 2 on the which states that "the conservation and restoration of monuments must have recourse to all the sciences and techniques, which can contribute to the study and safeguarding of the architectural heritage".

Furthermore, the Precision required and type of reports are also stated by Article 16 "in all works of preservation, restoration or excavation, there should always be precise documentation in the form of analytical and critical reports, illustrated with drawings and photographs. Every stage of the work of clearing, consolidation, rearrangement and integration, as well as technical and formal features identified while the work, should be included. This record should be placed in the archives of a public institution and made available to research workers. It is recommended that the report should be published".

Point out the following aspects 'precise documentation' in conservation works deals with the use of techniques that can acquire with precision and integrity the building and context geometry and texture.

The 'analytical and critical report' deals with the production of assessments about the actual condition of the subject, especially in the adequate quality of the measured dataset of geometric and texture for the thematic mapping.

In 1996, the ICOMOS principles set the grounds of the actual recording of historic buildings, as it defines: "Recording is the capture of information which describes the physical configuration, condition and use of monuments, groups of buildings and sites, at points in time, and it is an essential part of the conservation process".

According to the ICOMOS (1996) Principles for the Recording of Monuments, Groups of Buildings and Sites[6], recording should be undertaken:

- when compiling a national, regional, or local inventory;

- as a fully integrated part of research and conservation activity;

- before, during and after any works of repair, alteration, or other intervention, and when evidence of its history is revealed during such works;

- when total or partial demolition, destruction, abandonment or relocation is contemplated, or where the heritage is at risk of damage from human or natural external forces;

- during or following accidental or unforeseen disturbance which damages the cultural heritage;

- when change of use or responsibility for management or control occurs.

\subsection{International instruments to serve as guidelines to the practice}

The nomination of World Heritage sites is governed by the "Operational Guidelines, which are periodically revised to reflect the decisions of UNESCO's World Heritage Committee". As the World Heritage Convention is ratified and applied in more than 188 countries [7] this makes these guidelines the most recognized standards worldwide.
According to these guidelines, the following issues need to be provided at submission of a new nomination:

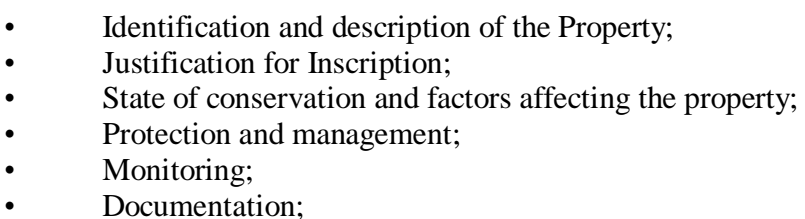

In terms of the boundaries, the Guidelines clearly state: "The boundaries of the property being proposed shall be clearly defined, unambiguously distinguishing between the nominated property and any buffer zone (when present). Maps shall be sufficiently detailed to determine precisely which area of land and/or water is nominated"

Furthermore, "All necessary documentation to substantiate the nomination shall be provided. In addition to what is indicated above, this shall include photographs, $35 \mathrm{~mm}$ slides, and image inventory and photograph authorization form. The text of the nomination shall be transmitted in printed form as well as in electronic format (Diskette or CD-Rom)".

Further, the RecorDIM) [8] initiative has provided the opportunity to documentation and conservation professionals to improve the practice of collecting, processing and managing information for conservation of architectural heritage. The results presented in this manual show the use of technology specifically used for capturing our cultural heritage, effectively providing a reference source for applying metric survey tools for conservation of architectural heritage.

As part of the deliverables of this initiative, The Getty Conservation and partners have made the following two publications: Guiding Principles Recording, Documentation, and Information Management for the Conservation of Heritage Places [9] and Illustrated Examples Recording, Documentation, and Information Management for the Conservation of Heritage Places [10].

These two guidelines provide the grounds for the understanding, planning and implementation of heritage recording, documentation and information systems projects.

In particular the Guiding principles provides the following key definitions for:

- Documentation: The already existing stock of information. As an activity, it stands for the systematic collection and archiving of records in order to preserve them for future reference. It can be said: Today's recording is tomorrow's documentation.

- Heritage information: The integrated activities of recording, documentation, and information management. Heritage recording: The graphic or photographic capturing of information describing the physical configuration, evolution, and condition of a heritage at known points in time.

- Information management: The process of finding, cataloguing, storing, and sharing information by making it accessible to potential users now and in the future.

Recording: Used in this publication in a broad sense, meaning the acquisition of new information deriving from all activities on a heritage asset, including heritage recording, research and investigation, conservation, use and management, and maintenance and monitoring. 
Research and investigation: Used to describe in general a variety of activities aimed at the acquisition of information pertinent to increasing knowledge of a cultural heritage place. While research is related more to off-site surveys (e.g., archival research), investigation relates to the direct acquisition of information from the heritage place as a primary source. Recording is an essential component of research and investigation at each step and at each level of the conservation process.

\subsection{Guidance on inventory and documentation of the cultural heritage (2009)}

The Council of Europe's Guidance on inventory and documentation of the cultural heritage6 expresses that inventories are "indispensable, for the purposes of identification, protection, interpretation, and physical preservation of movable objects, historic buildings, archaeological sites, and cultural landscapes" [11]. This book provides not only a detailed explanation of inventories, but also a standard on how to produce records. Any organization starting a heritage resources inventory should obtain a copy of this book.

\subsection{Assessing heritage places}

The protection of heritage places is only possible when these resources are included in pre-inventories, inventories, national register, world heritage list or other legal instruments that identify the significance and integrity at national, regional and/or international levels.

The action of recording or as better called "heritage places assessment" involves the identification and definition of character defining elements that assist in elaborating a "statement of significance", as well as, the analysis of risks affecting the integrity of the site and the actual state of conservation.

In particular, to heritage assessment, the relation between significance and integrity plays an essential role; Figure 3 illustrates this relation to evaluate a site and defining the heritage place's statement of significance, which is evidenced by the degree of evidences that these aspects (significance) are present in the fabric (integrity). One of the common tools for assessing this is using the Nara Grid approach developed by Van Balen and based on the Nara Authenticity Document [12], here the attributes are confronted with dimensions generating a multilayered approach to define the statement of significance of any historic place.

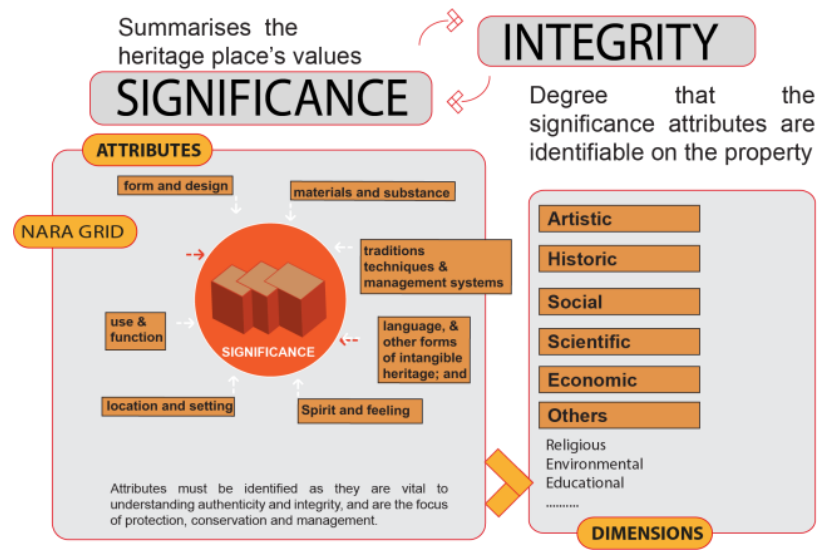

Figure 5: Nara Grid [12]
The Nara approach is very effective, but requires careful study, sufficient historic information and a consist approach. The combination of this study and measured records are used in the preparation of an evaluation plan, later in this article an example is provided developed at the Raymond Lemaire International Centre for Conservation (University of Leuven).

The evaluation of these threats will provide several indicators allowing defining the information heritage needs for this heritage place.

In addition, indicators can be used for ensuring a monitoring system, where a heritage information system will play a crucial role to record information about these indicators.

A heritage place conservation plan can be implemented using different approaches, this will shape the form and specification of the required "digital record" to be produced.

When recording heritage places, the following principles should be considered:

- "The property (site)" is the primary source of information $\&$ secondary is historic documents and iconography;

- Interdisciplinary collaboration \& partnership are crucial to develop approaches for maintaining/protecting heritage's Integrity;

- It is essential to analyse the why, when, where \& what to develop "how" accordingly;

- Appropriate, timely \& sufficient information permits informed decisions.

A digital record can be used as a baseline, as a starting point for designing and implementing a monitoring strategy, allowing detecting alterations affecting the character defining elements' physical integrity.

For example, a digital record would contain a report and a dossier of measured drawings (digital and printed) that could include a site plan, emplacement plan, plans of features, sections, elevations, three-dimensional models, Building Information Models (BIM), etc.

The selection of tool(s) for producing this digital record requires a careful study of variables associated with the characteristics of sites (resources). These should be provided by the study of indicators to be mapped and the level of detail defined for the baseline measured representation dataset.

These resource variables should be compared with the technology (sensors) and available and accessible at hand. Information plays an essential role in decision making for conservation. An adequate strategy for capturing, storing and managing that not only fulfils technical requirements, but also is also adapted to the institutional and staff potentials will be the most effective way.

The following aspects have been defined to provide a guideline for this selection:

- $\quad$ Heritage place;

- Organizational impact;

- Project;

- Tool. 
Heritage place variables: these variables deal with the accessibility of the site. As shown in Figure 9, a recording project will be impacted by the degree of time available to record on site, and this has a direct relation with the permitted (legal) time available, how to reach the site, height, extension, and the climatic conditions. For example, if the owner of the site allows recording the site only once a week for eight hours, and the level of record is detailed, this means that a faster technique capable of recording a great number of measurements is needed.

Team impact: these variables are associated to the current situation of the organization involved in the recording process, in many cases these variables assist in evaluating the need of outsourcing parts and/or the entire recording project.

Recording techniques require specific infrastructure and personnel skills to be use in a cost-effective way; this is a critical variable that is often neglected in many projects. A series of issues are explained in Figure 10, illustrating the impact of these variables.

Project variables: are aimed at defining what type of heritage information is to be recorded, according to the needs of an inventory, conservation strategy, preparation of a site management plan, maintenance plan, etc . The variables here presented and illustrated in figure 6 show key points to define the project needs, by evaluating the time, scale, consistency, extent and financial resources available for the work.

Tool (sensor, technique) variables: it is important to define the impact relation between the previous set of variables and the parameters they provide to select an adequate set of tools.

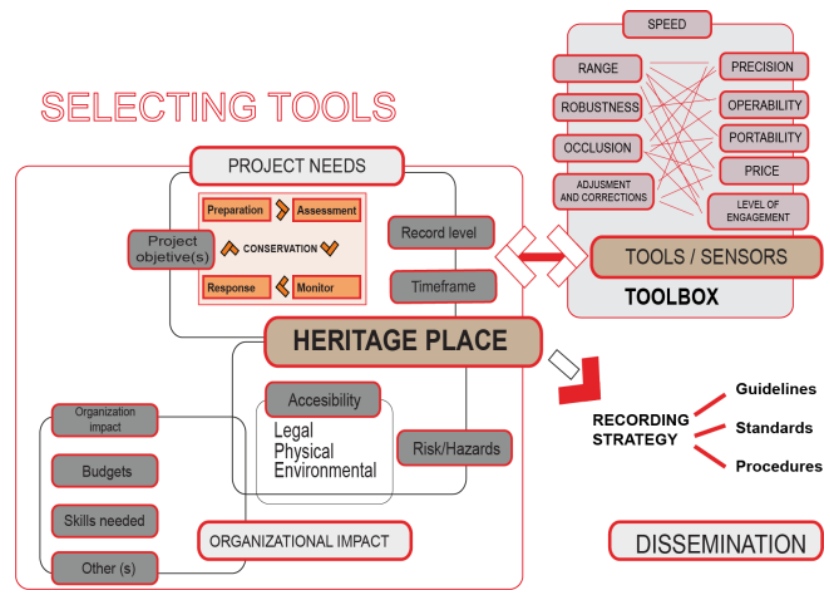

Figure 6: toolbox variables.

In figure 6 , a checklist of issues dealing with the operability of tools is provided, which list of issues allows to clarify the opportunities and limitations provided by:

- Speed: time to record an indicator

- Precision: accuracy factor of the capturing equipment.

- Measuring Range: reach of the tool, depends on distance and other environmental constraints.

- Field operability: constraints in relation to the fieldwork.

- Robustness: strength to extend adverse weather conditions and impact.

- Portability: capability of being transported to remote sites, requirements of transport, power and other factors. Adjustment and corrections: processes required to obtain accurate results.
- Occlusion: respond to shadows, obstacles, and material related constraints (reflectivity)

- Price: rental and/or purchase of the sensor

\section{DIGITIZING A HISTORIC PLACE IN A NUTSHELL}

An overview of the different fundamentals, issues and rules for recording heritage places have been provided throughout this paper, these aspects provide the grounds to understand what is needed and what it takes to be effective, however a basic question remains: where to start, what to record and how to proceed?

Figure 7 presents four main phases of work: planning, acquisition, processing and dissemination. Planning deals with assessing the site, objectives of the project and expected deliverables, as well as considerations of health and safety to conduct the survey. Acquisition deals with the capturing of the heritage places by first documenting the existing information of this asset, such as old drawings, iconographic sources, archives, old photographs and any other account of the history of the heritage place, which should be digitize.

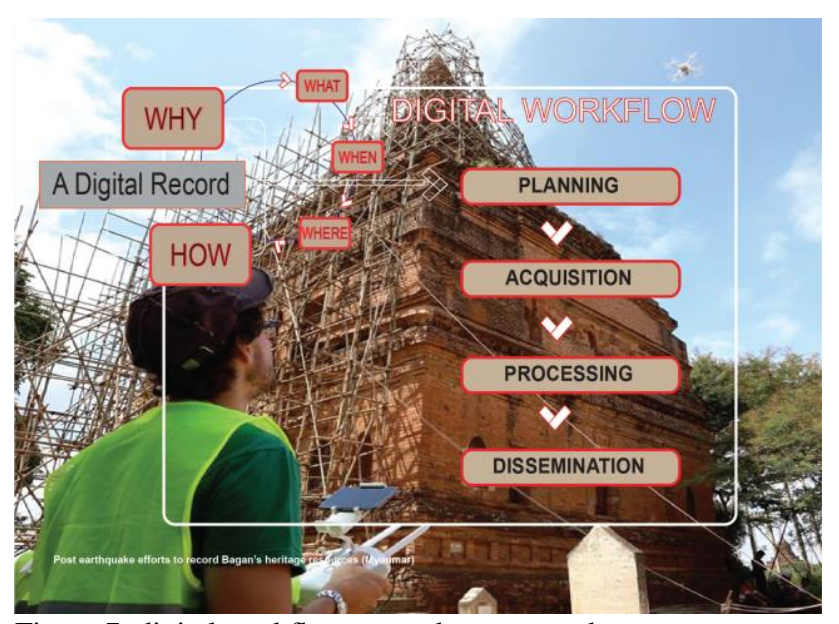

Figure 7: digital workflow to produce a record.

Recording, which is part of the acquisition phases involves capturing whatever is missing from the documentation part, as for example recording additional information, which is not depicted in existing drawings, updating the measured representations to the actual state of conservation of a historic building.

When recording, it is important to bear in mind the following statements and procedures:

- $\quad$ Nothing is straight, square or horizontal, this means that assumptions are not acceptable when recording heritage places;

- $\quad$ Record as-built condition: record only what you see (make difference between what you see and assumptions deduced from "logical" way of fabric);

- $\quad$ Record from the wide (big) to the small (fault theory);

- Record and provide provenance information;

- $\quad$ Create a BASIS and CONTROL system.

Furthermore, processing involves using either computer-aided drafting or Geographic Information Systems to combine the information collected for dissemination purposes.

Finally, making deliverables always carries out dissemination, these counts involve physical documents, localized databases or 
dynamic databases with spatial capacities, in Figure 13 these systems are depicted.

\section{BEST PRACTICES}

Four case studies will be presented during the presentation accompanying this paper, due to the constraint of paper length they are not described in detail here. The examples consist of:

- The preparation of records in case of Preparedness planning and post-disasters in Bagan, Myanmar:

- A digital record for conservation in the Kasbah of Taourirt, Morocco;

- A posterity record after conservation in the Tomb of Tutankhamen, Egypt; and

A baseline record for condition assessment in the Tomb of Nefartari, Egypt.

Each of these selected examples will illustrate the capacity and performance of a digital record to address the conservation needs.

\section{CONCLUDING REMARKS}

The application of digital techniques for the recording and visualization of heritage places is a powerful tool, however appropriate applications should access the conflicts and compromises of getting these techniques to deliver adequate heritage information for the not only disseminating these places, but conserving them. A good selection and application of recording and documentation tools is assured, when preparing a comprehensive approached derived from the needs of the expected site baseline. This base information set should take into consideration the indicators defined by assessing the state of conservator and statement of significant of the heritage place.

This contribution is aimed at providing an overview of the potential role that heritage information activities fit into the conservation process. Recording, documentation, and information management of heritage places are essential activities of all phases of conservation and should be fully integrated into this process.

Furthermore, all records resulting from this activity should be kept in a central repository and managed as part of an integrated project dossier.

Finally, a holistic approach, centered in the relevance of information to understand the significance, integrity and threats to our built heritage is of paramount importance. Values is a crucial concept in defining the extend and effective capturing and disseminating knowledge of heritage places.

\section{ACKNOWLEDGEMENTS}

The author wish to acknowledge and thank the support of many organizations in the compilation of this paper, such as the Getty Conservation Institute, Centre de conservation et réhabilitation du patrimoine architectural des zones atlasiques et sub-atlasiques (CERKAS), Myanmar's Department of Archaeology, National Museum and Library (DoA), the Association of Myanmar architects and UNESCO, Cyark foundation, and the Egypt's The Ministry of Antiquities. Further, acknowledge the hard work and crucial contribution of Davide Mezzino, Lori Chan, Luigi Barazzetti, Christian Ouimet, Alex Federman, Stephen Fai and the outstanding supporting staff of Carleton Immersive Media Studio (CIMS).

\section{REFERENCES}

[1] L. Chan and D. Mezzino, Myanmar: Architectural documentation of Historic Temples. Ottawa, Canada: Carleton Immersive Media Studio (CIMS), 2017.

[2] P. Canada. (2008). Standards and Guidelines for the conservation of historic places in Canada (2nd ed.). Available:

http://www.historicplaces.ca/en/pages/standardsnormes/document.aspx

[3] U. N. UN. (2016, 22/04). Sustainable Development Goals. Available: http://www.un.org/sustainabledevelopment/sustainabl e-development-goals/

[4] ICOMOS. (2017, 04/23). Report of the Istanbul Meeting on SDGs and Draft Action Plan: Cultural Heritage and Localizing the SDGs. Available: http://www.icomos.org/en/what-we-do/focus/unsustainable-development-goals/8776-report-of-theistanbul-meeting-on-sdgs-and-draft-action-plancultural-heritage-and-localizing-the-sdgs

[5] ICOMOS. (1964, Jan 18, 2015). The Venice Charter for the Conservation and Restoration of Monuments and Sites. Available: http://www.icomos.org/charters/venice_e.pdf

[6] ICOMOS. (1996, 11/15/2016). Principles for the Recording of monuments, groups of buildings and sites.

http://www.icomos.org/charters/archives-e.pdf

[7] UNESCO. (2016, 07/10). The Operational Guidelines for the Implementation of the World Heritage Convention.

Available: http://whc.unesco.org/en/guidelines/

[8] (2007, 11/15). RecorDIM (for Heritage Recording, Documentation and Information Management) Initiative Available: http://extranet.getty.edu/gci/recordim/index.html

[9] R. Letellier, W. Schmid, and F. LeBlanc, Guiding Principles Recording, Documentation, and Information Management for the Conservation of Heritage Places. Los Angeles, USA: Getty Conservation Institute, 2007.

[10] R. Eppich, A. Chabbi, and Getty Conservation Institute., Recording, documentation, and information management for the conservation of heritage places : illustrated examples. Los Angeles: Getty Conservation Institute, 2007.

[11] C. o. Europe, Guidance on inventory and documentation of the cultural heritage: Council of Europe, 2009.

[12] K. Van Balen, "An Evaluation Scheme Based on the Nara Document on Authenticity," Bulletin of the Association for Preservation Technology, vol. 39, p. 39, 2008. 